\title{
Performance of density functional theory methods to describe intramolecular hydrogen shifts
}

\author{
NELLY GONZÁLEZ-RIVAS and ANDRÉS CEDILLO* \\ Departamento de Química, UAM-Iztapalapa, San Rafael Atlixco 186, Iztapalapa DF 09340, México \\ e-mail: cedillo@xanum.uam.mx
}

\begin{abstract}
The performance of three exchange and correlation density functionals, LDA, BLYP and B3LYP, with four basis sets is tested in three intramolecular hydrogen shift reactions. The best reaction and activation energies come from the hybrid functional B3LYP with triple- $\zeta$ basis sets, when they are compared with high-level post-Hartree-Fock results from the literature. For a fixed molecular geometry, the electrophilic Fukui function is computed from a finite difference approximation. Fukui function shows a small dependence with both the exchange and correlation functional and the basis set. Evolution of the Fukui function along the reaction path describes important changes in the basic sites of the corresponding molecules. These results are in agreement with the chemical behavior of those species.
\end{abstract}

Keywords. DFT performance; intramolecular hydrogen shifts; Fukui function.

\section{Introduction}

Chemical compounds present different types of isomerism. When two isomers differ by the placement of an atom or a functional group and an interconversion equilibrium is established, this process is referred as a tautomeric equilibrium and the isomers are known as tautomers. ${ }^{1,2}$ Tautomerism arising from a hydrogen shift occurs frequently in many chemical systems, such as keto-enol and imine-enamine equilibrium, aminoacid zwiterionic forms, metabolic intermediates. ${ }^{3}$ In these processes an intramolecular proton transfer occurs, where a hydrogen ion jumps from one atom to another atom of the same molecule. The reactions $\mathrm{HAB} \leftrightarrow \mathrm{ABH}$ and $\mathrm{HABC} \leftrightarrow \mathrm{ABCH}$ exemplify the 1,2 and 1,3 hydrogen shifts respectively. The study of tautomerism has been very useful in rationalizing some aspects of the chemical bond, mainly because the proton is able to form a chemical bond with two different atoms of the same molecule and, in most of the cases, the stability of both isomers is different. ${ }^{4}$ The stability strongly depends on the environment. For aminoacids, the neutral isomer is more stable than the zwiterion in the gas phase, but in aqueous solution the zwiterion is the stable form. In addition, the molecular structure of zwiterions and peptides depends on the acidity of the solution.

*For correspondence
In the literature one can find several theoretical studies of tautomerism. ${ }^{5-8}$ These studies confirm the established stability trends and they are mainly interested in the energy of the processes. ${ }^{5,6}$ In some cases, the transition state for the gas phase reaction is presented and the relationship with the Hammond Principle is also analyzed. ${ }^{7}$ The evolution of molecular properties along the reaction path has also been described for some systems with keto-enol equilibrium. ${ }^{8}$

In a tautomeric process, the proton moves from one atom to another. Note that this hydrogen ion can be identified as a Lewis acid, while the protonation site corresponds to a Lewis basic site. During the transfer process, molecular properties evolve, as a consequence of the breaking and formation of chemical bonds, and the reactivity of the molecule changes. Since the proton usually binds to basic sites, it is very important to locate and characterize this kind of reactive sites, as well as their evolution along the process. Density function theory (DFT) provides reactivity parameters ${ }^{9}$ which are useful in the understanding of Lewis acid-base behavior of molecules. For a detailed description of the regions of the molecule, the Fukui function is able to locate Lewis acidic and basic sites. ${ }^{10}$

In the present work we analyze of the performance of DFT methods to describe intramolecular hydrogen shifts. Three small molecules $\left(\mathrm{HCl}-\mathrm{O}, \mathrm{H}_{2} \mathrm{~S}=\mathrm{O}\right.$ and $\mathrm{H}_{3} \mathrm{C}-\mathrm{CH}=\mathrm{O}$ ) were selected to test the ability of three density functionals, with four basis sets, to describe molecular geometries of both tautomers and the cor- 
Table 1. Reaction and activation energies, in $\mathrm{kcal} \mathrm{mol}^{-1}$.

\begin{tabular}{|c|c|c|c|c|c|c|c|}
\hline & & & B1 & B2 & B3 & B4 & Ref \\
\hline $\mathrm{H}_{2} \mathrm{SO}$ & $\begin{array}{l}\text { HF } \\
\text { LDA } \\
\text { BLYP } \\
\text { B3LYP }\end{array}$ & $\begin{array}{l}\Delta E_{r} \\
\Delta E^{\dagger} \\
\Delta E_{r} \\
\Delta E^{\dagger} \\
\Delta E_{r} \\
\Delta E^{\dagger} \\
\Delta E_{r} \\
\Delta E^{\dagger}\end{array}$ & $\begin{array}{r}-32 \cdot 4 \\
53 \cdot 8 \\
-21 \cdot 7 \\
38 \cdot 2 \\
-22 \cdot 3 \\
38 \cdot 8 \\
-25 \cdot 3 \\
41 \cdot 9\end{array}$ & $\begin{array}{r}-21 \cdot 6 \\
58 \cdot 4 \\
-14.4 \\
38 \cdot 6 \\
-15 \cdot 5 \\
40 \cdot 1 \\
-17 \cdot 1 \\
44 \cdot 0\end{array}$ & $\begin{array}{r}-32 \cdot 8 \\
48 \cdot 2 \\
-23 \cdot 7 \\
32 \cdot 0 \\
-24 \cdot 6 \\
33 \cdot 1 \\
-27 \cdot 0 \\
36 \cdot 2\end{array}$ & $\begin{array}{r}-24 \cdot 2 \\
55 \cdot 5 \\
-17 \cdot 9 \\
36 \cdot 2 \\
-18 \cdot 8 \\
37 \cdot 6 \\
-20 \cdot 6 \\
41 \cdot 4\end{array}$ & $\begin{array}{r}-18 \cdot 3 \\
43 \cdot 7\end{array}$ \\
\hline $\mathrm{HClO}$ & $\begin{array}{l}\text { HF } \\
\text { LDA } \\
\text { BLYP } \\
\text { B3LYP }\end{array}$ & $\begin{array}{l}\Delta E_{r} \\
\Delta E^{\dagger} \\
\Delta E_{r} \\
\Delta E^{\dagger} \\
\Delta E_{r} \\
\Delta \mathrm{E}^{\dagger} \\
\Delta E_{r} \\
\Delta E^{\dagger}\end{array}$ & $\begin{array}{r}-68 \cdot 3 \\
17 \cdot 2 \\
-61 \cdot 8 \\
21 \cdot 1 \\
-62 \cdot 5 \\
18 \cdot 6 \\
-65 \cdot 2 \\
15 \cdot 9\end{array}$ & $\begin{array}{r}-58 \cdot 7 \\
23 \cdot 5 \\
-48 \cdot 0 \\
20 \cdot 6 \\
-50 \cdot 5 \\
18 \cdot 4 \\
-52 \cdot 5 \\
20 \cdot 3\end{array}$ & $\begin{array}{r}-62 \cdot 9 \\
16 \cdot 5 \\
-55 \cdot 0 \\
15 \cdot 6 \\
-56 \cdot 2 \\
13 \cdot 7 \\
-58 \cdot 4 \\
14 \cdot 9\end{array}$ & $\begin{array}{r}-62 \cdot 3 \\
21 \cdot 3 \\
-50 \cdot 8 \\
18 \cdot 6 \\
-52 \cdot 7 \\
16 \cdot 6 \\
-54 \cdot 7 \\
18 \cdot 3\end{array}$ & $\begin{array}{r}-53 \cdot 4 \\
22 \cdot 7\end{array}$ \\
\hline $\mathrm{CH}_{3} \mathrm{CHO}$ & $\begin{array}{l}\text { HF } \\
\text { LDA } \\
\text { BLYP }\end{array}$ & $\begin{array}{l}\Delta E_{r} \\
\Delta E^{\dagger} \\
\Delta E_{r} \\
\Delta E^{\dagger} \\
\Delta E_{r} \\
\Delta E^{\dagger} \\
\Delta E_{r} \\
\Delta E^{\dagger}\end{array}$ & $\begin{array}{l}17 \cdot 0 \\
90 \cdot 0 \\
11 \cdot 7 \\
59 \cdot 0 \\
15 \cdot 6 \\
68 \cdot 0 \\
15 \cdot 3 \\
72 \cdot 8\end{array}$ & $\begin{array}{r}12.0 \\
85.9 \\
6.3 \\
55.1 \\
9.7 \\
64.6 \\
9.6 \\
68.8\end{array}$ & $\begin{array}{r}12.1 \\
85.6 \\
6.1 \\
54.5 \\
9.6 \\
63.6 \\
9.6 \\
68.0\end{array}$ & $\begin{array}{r}11.7 \\
85.7 \\
6.1 \\
56 \cdot 0 \\
9.6 \\
64.5 \\
9.4 \\
68.7\end{array}$ & $\begin{array}{l}10 \cdot 4 \\
70 \cdot 2\end{array}$ \\
\hline
\end{tabular}

B1: 6-31g $(d)$; B2: 6-311++g(3df, 3pd); B3: aug-cc- $p$ VDZ; B4: aug-cc- $p$ VTZ; Ref: see description in text

responding transition state and the reaction and activation energy of these processes. Previous works in the literature show that DFT provides good results for energetics, geometries and vibrational frequencies. ${ }^{6}$ In addition, the electrophilic Fukui function, $f^{-}$, for tautomers and transition states is also computed and its dependence with the computational method is analyzed, as well as the evolution along the reaction. The results are contrasted with post HartreeFock values reported in the literature.

\section{Methodology}

All the results were calculated with NWChem package. ${ }^{11}$ A frequency analysis was applied to optimized and transition state geometries to verify the stability criterion. The selected exchange and correlation functionals for DFT Kohn-Sham calculations were LDA, ${ }^{12} \mathrm{BLYP}^{13,14}$ and B3LYP, ${ }^{14,15}$ in order to include functionals without and with gradient corrections and a hybrid one. Four basis sets were used with each functional, two Pople's sets, a small one, 6$3 \lg (d)(\mathrm{B} 1)$, and a large one, 6-311++g( $3 d f, 3 p d)$
(B2), and two Dunning's sets, aug-cc-pVDZ (B3) and aug-cc-pVTZ (B4). Hartree-Fock results were also included in the comparison with all the basis sets.

A finite differences approximation is used for the calculation of the electrophilic Fukui functions, $f^{-}(r)=(\partial \rho(r) / \partial N)_{v}^{-} \approx \rho_{N}(r)-\rho_{N-1}(r)$, where $\rho_{N}$ and $\rho_{N-1}$ are the densities of the neutral molecule and the vertical cation, respectively.

\section{Results}

For each method, a geometry optimization was performed for the tautomers and a saddle point search was made for the transition state. Reaction and activation energies for the three reactions are reported in table 1. Reported geometries were found in the literature for the same species, a $\operatorname{CCSD}(\mathrm{T}) /$ $6-311++\mathrm{g}(3 d f, 3 p d)$ calculation for the reaction $\mathrm{HCl}-$ $\mathrm{O} \leftrightarrow \mathrm{Cl}-\mathrm{OH} ;{ }^{16} \quad \mathrm{CASSCF} / 6-311++\mathrm{g}(3 d f, 3 p d)$ for $\mathrm{H}_{2} \mathrm{~S}=\mathrm{O} \leftrightarrow \mathrm{HS}-\mathrm{OH} ;{ }^{17}$ and MP2/6-311+g $(d, p)$ for the keto-enol tautomerism of acetaldehyde, $\mathrm{H}_{3} \mathrm{C}-\mathrm{CH}=\mathrm{O} \leftrightarrow$ $\mathrm{H}_{2} \mathrm{C}=\mathrm{CH}-\mathrm{OH} .{ }^{18}$ These geometries are used as refer- 
Table 2. Relevant geometrical parameters of the optimized structures, distances in angstroms and angles in degrees.

\begin{tabular}{|c|c|c|c|c|c|c|c|c|}
\hline & & \multirow[b]{2}{*}{ Ref. } & \multicolumn{3}{|c|}{ B3LYP } & \multicolumn{3}{|c|}{ BLYP } \\
\hline & & & B2 & B3 & B4 & B2 & B3 & B4 \\
\hline \multirow[t]{3}{*}{$\mathrm{HCl}-\mathrm{O}$} & $r_{\mathrm{ClO}}$ & 1.568 & 1.565 & 1.630 & 1.587 & 1.585 & 1.649 & 1.606 \\
\hline & $r_{\mathrm{HCl}}$ & $1 \cdot 308$ & $1 \cdot 320$ & $1 \cdot 331$ & $1 \cdot 323$ & $1 \cdot 345$ & $1 \cdot 359$ & $1 \cdot 347$ \\
\hline & $\alpha_{\mathrm{HClO}}$ & $107 \cdot 6$ & $108 \cdot 1$ & $106 \cdot 8$ & $107 \cdot 6$ & $109 \cdot 0$ & $108 \cdot 0$ & $108 \cdot 6$ \\
\hline \multirow[t]{3}{*}{$\mathrm{TS}$} & $r_{\mathrm{ClO}}$ & $1 \cdot 764$ & $1 \cdot 761$ & $1 \cdot 808$ & $1 \cdot 776$ & 1.778 & $1 \cdot 821$ & 1.791 \\
\hline & $r_{\mathrm{HCl}}$ & $1 \cdot 314$ & $1 \cdot 322$ & $1 \cdot 330$ & $1 \cdot 324$ & $1 \cdot 327$ & $1 \cdot 335$ & $1 \cdot 328$ \\
\hline & $\alpha_{\mathrm{HClO}}$ & $62 \cdot 5$ & $65 \cdot 3$ & $63 \cdot 0$ & $62 \cdot 3$ & $64 \cdot 7$ & $65 \cdot 9$ & $64 \cdot 9$ \\
\hline \multirow[t]{3}{*}{$\mathrm{Cl}-\mathrm{OH}$} & $r_{\mathrm{ClO}}$ & 1.699 & $1 \cdot 700$ & 1.731 & $1 \cdot 708$ & $1 \cdot 736$ & $1 \cdot 767$ & 1.744 \\
\hline & $r_{\mathrm{HO}}$ & 0.964 & $0 \cdot 967$ & 0.971 & 0.967 & 0.978 & 0.982 & 0.978 \\
\hline & $\alpha_{\mathrm{ClOH}}$ & $102 \cdot 9$ & $103 \cdot 6$ & $102 \cdot 8$ & $103 \cdot 3$ & $102 \cdot 5$ & $101 \cdot 8$ & $102 \cdot 1$ \\
\hline \multirow[t]{3}{*}{$\mathrm{H}_{2} \mathrm{~S}=\mathrm{O}$} & $r_{\mathrm{SO}}$ & $1 \cdot 484$ & $1 \cdot 485$ & 1.537 & 1.499 & $1 \cdot 504$ & $1 \cdot 555$ & 1.519 \\
\hline & $r_{\mathrm{SH}}$ & $1 \cdot 356$ & $1 \cdot 382$ & $1 \cdot 398$ & $1 \cdot 385$ & $1 \cdot 401$ & $1 \cdot 420$ & 1.404 \\
\hline & $\alpha_{\mathrm{HSO}}$ & $108 \cdot 9$ & $108 \cdot 6$ & $107 \cdot 8$ & $108 \cdot 3$ & $108 \cdot 8$ & $108 \cdot 0$ & $108 \cdot 4$ \\
\hline \multirow[t]{3}{*}{ TS } & $r_{\mathrm{SO}}$ & 1.665 & $1 \cdot 657$ & $1 \cdot 711$ & 1.672 & $1 \cdot 684$ & 1.734 & 1.698 \\
\hline & $r_{\mathrm{SH}}$ & $1 \cdot 389$ & 1.403 & 1.410 & 1.430 & 1.413 & $1 \cdot 418$ & $1 \cdot 145$ \\
\hline & $\alpha_{\mathrm{HSO}}$ & $104 \cdot 9$ & $104 \cdot 5$ & $103 \cdot 4$ & $104 \cdot 14$ & $104 \cdot 9$ & $104 \cdot 1$ & $104 \cdot 5$ \\
\hline \multirow[t]{3}{*}{$\mathrm{HS}-\mathrm{OH}$} & $r_{\mathrm{SO}}$ & 1.678 & 1.674 & 1.715 & 1.684 & 1.705 & 1.745 & 1.715 \\
\hline & $r_{\mathrm{OH}}$ & 0.967 & $0 \cdot 964$ & 0.968 & 0.964 & 0.975 & 0.978 & 0.974 \\
\hline & $\alpha_{\mathrm{HSO}}$ & $106 \cdot 4$ & $107 \cdot 8$ & $106 \cdot 6$ & $107 \cdot 5$ & $106 \cdot 7$ & $105 \cdot 6$ & $106 \cdot 4$ \\
\hline \multirow[t]{4}{*}{$\mathrm{H}_{3} \mathrm{C}-\mathrm{CH}=\mathrm{O}$} & $r_{\mathrm{CO}}$ & $1 \cdot 200$ & $1 \cdot 202$ & $1 \cdot 210$ & $1 \cdot 204$ & $1 \cdot 215$ & $1 \cdot 223$ & $1 \cdot 216$ \\
\hline & $r_{\mathrm{CC}}$ & 1.490 & $1 \cdot 501$ & $1 \cdot 504$ & $1 \cdot 500$ & $1 \cdot 511$ & $1 \cdot 514$ & $1 \cdot 511$ \\
\hline & $r_{\mathrm{CH}}$ & 1.090 & 1.093 & $1 \cdot 101$ & 1.093 & 1.093 & $1 \cdot 108$ & $1 \cdot 100$ \\
\hline & $\alpha_{\mathrm{HCC}}$ & $110 \cdot 6$ & $111 \cdot 0$ & $111 \cdot 0$ & $111 \cdot 1$ & $111 \cdot 2$ & $111 \cdot 2$ & $111 \cdot 2$ \\
\hline \multirow[t]{4}{*}{ TS } & $r_{\mathrm{CO}}$ & $1 \cdot 280$ & $1 \cdot 276$ & $1 \cdot 284$ & $1 \cdot 277$ & $1 \cdot 293$ & $1 \cdot 300$ & $1 \cdot 294$ \\
\hline & $r_{\mathrm{CC}}$ & 1.400 & 1.408 & $1 \cdot 415$ & 1.408 & $1 \cdot 415$ & 1.422 & 1.414 \\
\hline & $r_{\mathrm{CH}}$ & 1.480 & $1 \cdot 502$ & 1.507 & $1 \cdot 501$ & 1.520 & 1.526 & 1.520 \\
\hline & $\alpha_{\mathrm{HCC}}$ & $65 \cdot 05$ & $66 \cdot 8$ & $66 \cdot 9$ & $66 \cdot 8$ & $67 \cdot 2$ & $67 \cdot 3$ & $67 \cdot 2$ \\
\hline \multirow[t]{4}{*}{$\mathrm{H}_{2} \mathrm{C}=\mathrm{CH}-\mathrm{OH}$} & $r_{\mathrm{CO}}$ & $1 \cdot 350$ & $1 \cdot 375$ & $1 \cdot 381$ & $1 \cdot 376$ & $1 \cdot 360$ & $1 \cdot 366$ & $1 \cdot 361$ \\
\hline & $r_{\mathrm{CC}}$ & $1 \cdot 330$ & $1 \cdot 338$ & $1 \cdot 347$ & $1 \cdot 337$ & $1 \cdot 327$ & $1 \cdot 337$ & $1 \cdot 327$ \\
\hline & $r_{\mathrm{OH}}$ & 0.960 & 0.974 & 0.978 & 0.974 & 0.964 & 0.967 & 0.964 \\
\hline & $\alpha_{\mathrm{HOC}}$ & $108 \cdot 1$ & $109 \cdot 2$ & $109 \cdot 0$ & $109 \cdot 2$ & $109 \cdot 8$ & $109 \cdot 5$ & $109 \cdot 8$ \\
\hline
\end{tabular}

B2: 6-311++g(3df, 3pd); B3: aug-cc- $p$ VDZ; B4: aug-cc- $p$ VTZ; Ref: see description in text

ences. Single point calculations were performed on each species with $\operatorname{CCSD}(\mathrm{T}) / 6-311++\mathrm{g}(3 d f, 3 p d)$ method on the reference geometry, in order to have reference energies at the same level of theory. These results are also included in table 1. A comparison of the values from table 1 shows that the small basis set (B1), 6$31 g(d)$, has the largest deviations from the reference values, while the triple- $\zeta$ basis sets, $6-311++\mathrm{g}(3 d f$, $3 p d$ ) (B2) and aug-cc-pvtz (B4), provide the best results in the set. On the other hand, BLYP and B3LYP results are closer to the reference values than HF and LDA ones. On the average, B3LYP/6-311++g $(3 d f, 3 p d)$ method provides the better relative energy values. Table 2 presents relevant geometric parameters from the optimized molecules together with reference values. This table only includes results from
BLYP and B3LYP methods, as these methods produce better relative energies. Again, one can note that triple- $\zeta$ basis sets, (B2) and (B4), provide better results. In contrast with Durant, ${ }^{6 a}$ we found that the BLYP functional is able to locate all the transition state structures with all the basis sets and the use of larger basis sets leads to better energy barriers, specifically, for the B3LYP/6-311++g(3df, 3pd) method the maximum difference with respect to the reference value is $-2.4 \mathrm{kcal} \mathrm{mol}^{-1}$. Our results coincide with previous studies on the same molecules where it is shown that DFT geometries are in good agreement with high-level $a b$ initio calculations ${ }^{6}$ and DFT methods usually underestimate barrier heights. ${ }^{6,19}$ However, the hybrid functional results are closer to the reference values. ${ }^{6}$ 
Table 3. Fukui function $M_{i j k}$ integrals of the transition state of the reaction $\mathrm{H}_{2} \mathrm{~S}=\mathrm{O} \leftrightarrow \mathrm{HS}-\mathrm{OH}$, in atomic units.

\begin{tabular}{|c|c|c|c|c|c|c|c|}
\hline & B3LYP/B1 & B3LYP/B2 & B3LYP/B3 & B3LYP/B4 & $\mathrm{HF} / \mathrm{B} 2$ & LDA/B2 & BLYP/B2 \\
\hline$M_{100}$ & $0 \cdot 13$ & $0 \cdot 10$ & $0 \cdot 10$ & $0 \cdot 10$ & $0 \cdot 09$ & $0 \cdot 10$ & $0 \cdot 10$ \\
\hline$M_{010}$ & $0 \cdot 05$ & $-0 \cdot 02$ & $-0 \cdot 02$ & $-0 \cdot 02$ & $0 \cdot 05$ & $-0 \cdot 04$ & -0.03 \\
\hline$M_{001}$ & 0.08 & $0 \cdot 14$ & $0 \cdot 15$ & $0 \cdot 14$ & $0 \cdot 26$ & $0 \cdot 07$ & 0.09 \\
\hline$M_{200}$ & $2 \cdot 32$ & $2 \cdot 59$ & $2 \cdot 60$ & $2 \cdot 62$ & $2 \cdot 42$ & $2 \cdot 65$ & $2 \cdot 67$ \\
\hline$M_{110}$ & $-0 \cdot 07$ & $-0 \cdot 07$ & $-0 \cdot 08$ & -0.07 & $-0 \cdot 04$ & $-0 \cdot 11$ & $-0 \cdot 09$ \\
\hline$M_{101}$ & $-0 \cdot 43$ & $-0 \cdot 41$ & $-0 \cdot 42$ & $-0 \cdot 42$ & $-0 \cdot 36$ & $-0 \cdot 42$ & $-0 \cdot 42$ \\
\hline$M_{020}$ & $2 \cdot 95$ & $3 \cdot 36$ & $3 \cdot 39$ & $3 \cdot 39$ & $3 \cdot 10$ & $3 \cdot 47$ & $3 \cdot 48$ \\
\hline$M_{011}$ & $-0 \cdot 10$ & $0 \cdot 05$ & $0 \cdot 02$ & $0 \cdot 04$ & $0 \cdot 34$ & -0.06 & $-0 \cdot 04$ \\
\hline$M_{002}$ & $5 \cdot 28$ & $5 \cdot 95$ & $6 \cdot 02$ & $5 \cdot 98$ & $6 \cdot 05$ & $5 \cdot 88$ & $5 \cdot 94$ \\
\hline
\end{tabular}

B1: 6-31g $(d)$; B2: 6-311++g(3df, 3pd); B3: aug-cc- $p$ VDZ; B4: aug-cc- $p$ VTZ
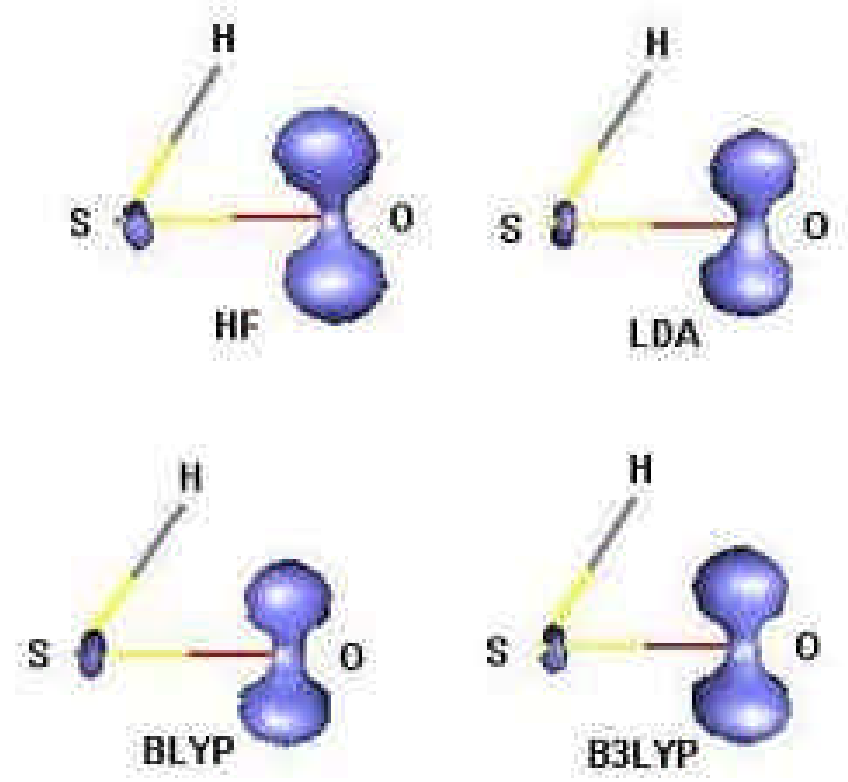

Figure 1. Fukui function $f^{-}$isosurfaces (isosurface value: 0.03 ) of the transition state of the reaction $\mathrm{H}_{2} \mathrm{~S}=\mathrm{O} \leftrightarrow \mathrm{HS}-\mathrm{OH}$, calculated with different methods and the same basis set, 6-311++g(3df, 3pd).

In order to analyze the dependence of the Fukui function on the computational method, for every method, the Fukui function is calculated for the reference geometries. A quantitative comparison can be made using the moments of the involved densities,

$$
\begin{aligned}
M_{i j k} & \equiv \int x^{i} y^{j} z^{k} f^{-}(r) \mathrm{d} r \\
& =\int x^{i} y^{j} z^{k} \rho_{N}(r) \mathrm{d} r-\int x^{i} y^{j} z^{k} \rho_{N-1}(r) \mathrm{d} r .
\end{aligned}
$$

Values of the $M_{i j k}$ integrals show a higher dependence on the method, while, for a given method, the basis set has smaller effects. We found that larger variations in $M_{i j k}$ integrals occur in transition states. As a representative case, table 3 presents the values of the $M_{i j k}$ integrals for the transition state of the reaction $\mathrm{H}_{2} \mathrm{~S}=\mathrm{O} \leftrightarrow \mathrm{HS}-\mathrm{OH}$. One can note that large basis sets give similar results, on the other hand, DFT methods produce closer values, while HF results are a little farther. The same analysis was made in the moments of the densities, since variations are smaller, they are not tabulated. A graphical comparison of the same cases can be found in figures 1 and 2, where isosurfaces of the Fukui function are represented. The Fukui function is evaluated in a three-dimensional grid, from density grids of the neutral and positive ion. All the isosurfaces are computed at the same positive value. Figure 1 represents the effect of the method on the Fukui function, while in figure 2 the basis set is changed. All the isosurfaces look alike, except for the HF isosurface, which seems to be a little larger. The difference between HF and DFT results is in agreement with the analysis of the values from table 3 . This behavior is found to be in agreement with a previous study, ${ }^{20}$ where the effect of correlation in the Fukui function is analyzed.

The evolution of the Fukui function for the three reactions is shown in figures 3-5. In figure 3 one can see that, for the reaction $\mathrm{HCl}-\mathrm{O} \leftrightarrow \mathrm{Cl}-\mathrm{OH}$, the reactant's basicity is mainly located at the oxygen atom, but, after the hydrogen shifts from chlorine to oxygen, basicity appears on the chlorine atom and decreases at the oxygen. One can note that oxygen's donating capacity is still larger than chlorine's in the product. In addition, the transition state basicity is mainly located at the oxygen atoms. Figure 4 show a similar behavior for the reaction $\mathrm{H}_{2} \mathrm{~S}=\mathrm{O} \leftrightarrow \mathrm{HS}-\mathrm{OH}$, except for the basicity of the product. In $\mathrm{HS}-\mathrm{OH}$ 
molecule, both oxygen and sulfur are singly protonated, but the Fukui function is larger on the sulfur atom, in agreement with the fact that sulfur is more basic than oxygen. For the reaction $\mathrm{H}_{3} \mathrm{C}-\mathrm{CH}=\mathrm{O} \leftrightarrow$ $\mathrm{H}_{2} \mathrm{C}=\mathrm{CH}-\mathrm{OH}$, one can see that, in the reactant, the
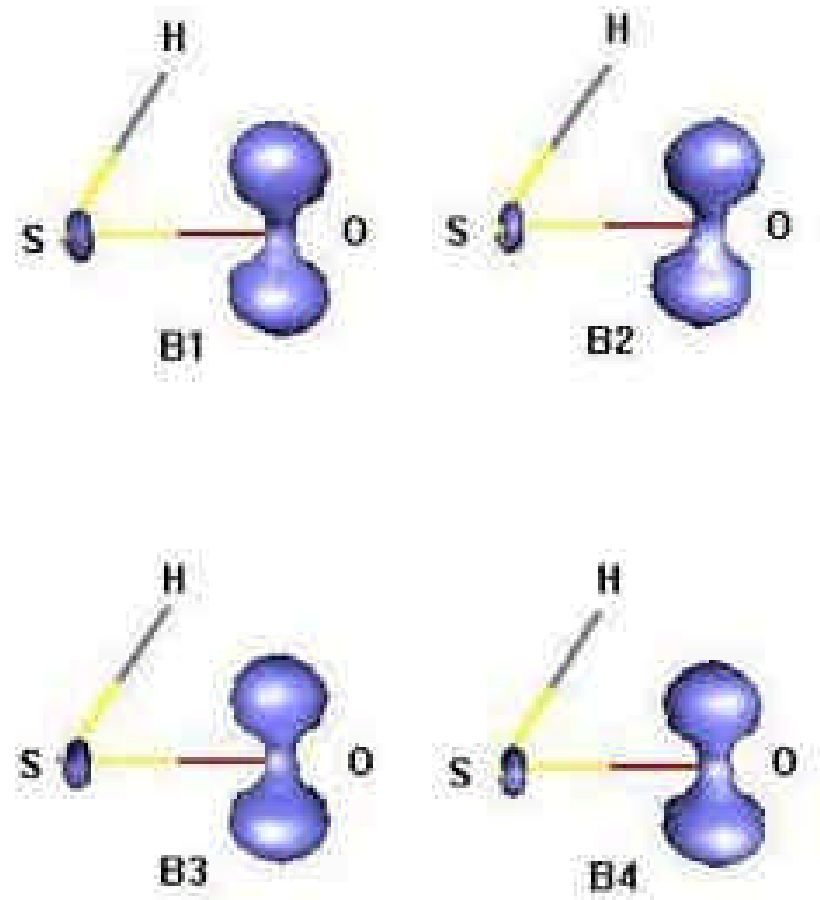

Figure 2. Fukui function $f^{-}$isosurfaces (isosurface value: 0.03 ) of the transition state of the reaction $\mathrm{H}_{2} \mathrm{~S}=\mathrm{O} \leftrightarrow \mathrm{HS}-\mathrm{OH}$, calculated with different basis sets and the B3LYP method.

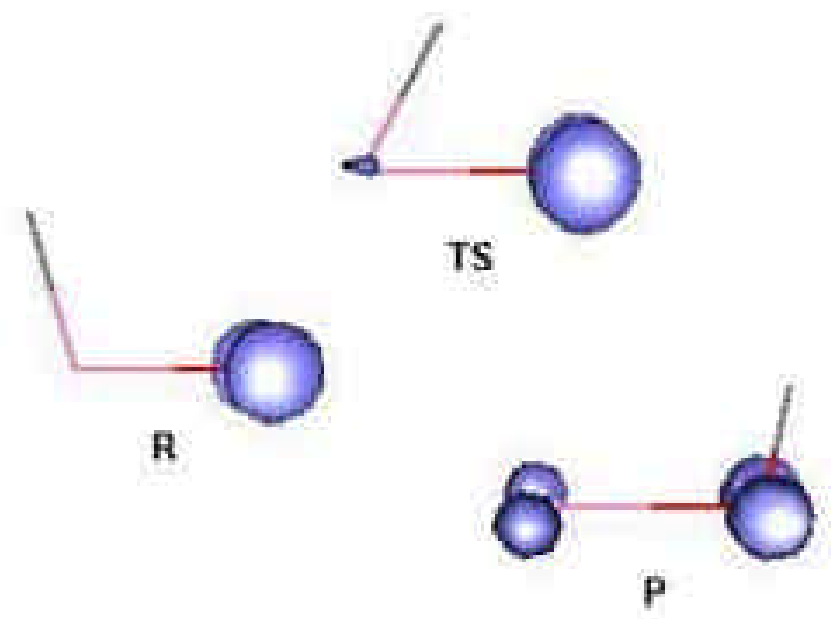

Figure 3. Fukui function $f^{-}$isosurfaces (isosurface value: 0.03) of the tautomers and transition state of the reaction $\mathrm{HCl}-\mathrm{O} \leftrightarrow \mathrm{Cl}-\mathrm{OH}$, calculated at the $\mathrm{B} 3 \mathrm{LYP} /$ 6-311++g $(3 d f, 3 p d)$ level. basic character is manly located at the oxygen of the carbonyl group. At the transition state, the $\alpha$-carbon atom enhances its basicity, while the oxygen basicity decreases. The product shows similar donating capacities on oxygen and $\alpha$-carbon atoms and the orientation of the Fukui function isosurface is normal to the molecular plane, a consequence of the conjugation on the enol.
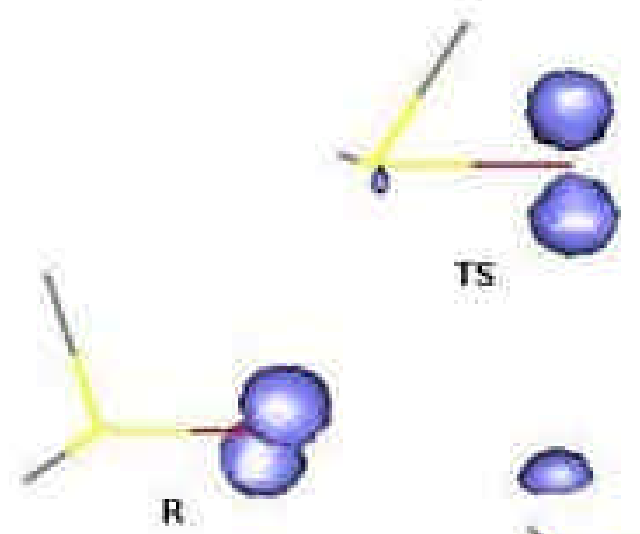

IS

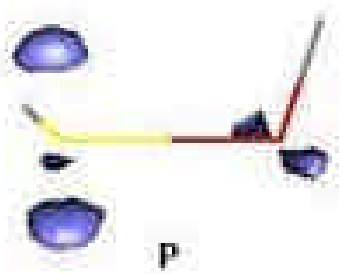

Figure 4. Fukui function $f^{-}$isosurfaces (isosurface value: 0.03 ) of the tautomers and transition state of the reaction $\mathrm{H}_{2} \mathrm{~S}=\mathrm{O} \leftrightarrow \mathrm{HS}-\mathrm{OH}$, calculated at the B3LYP/ $6-311++\mathrm{g}(3 d f, 3 p d)$ level.

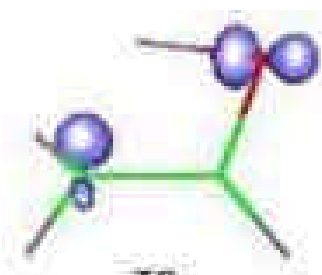

IS
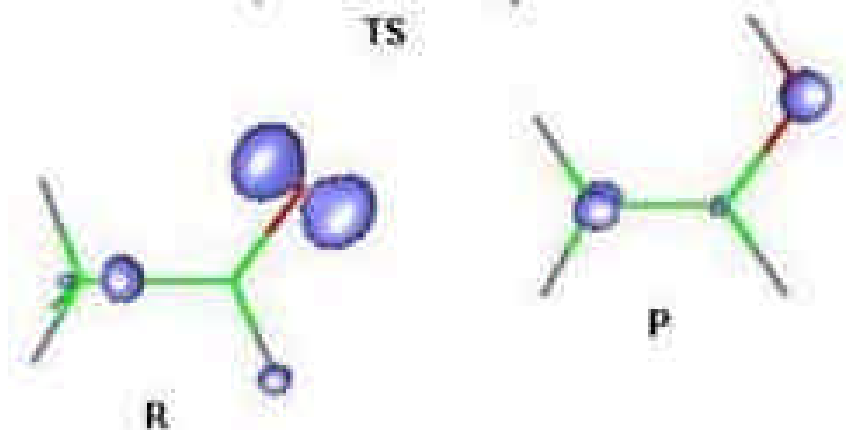

Figure 5. Fukui function $f$ isosurfaces (isosurface value: 0.03 ) of the tautomers and transition state of the reaction $\mathrm{H}_{3} \mathrm{C}-\mathrm{CH}=\mathrm{O} \leftrightarrow \mathrm{H}_{2} \mathrm{C}=\mathrm{CH}-\mathrm{OH}$, calculated at the B3LYP/6-311++g(3df, 3pd) level. 
Comparison of the Fukui function isosurfaces for each reaction shows that the transition state has a closer resemblance to the reactant in figures 3 and 4 . With his criterion, both reactions correspond to the Hammond type, in agreement with relative displacement of the proton with respect to both basic sites in the transition state. These results are also in accordance with the Brönsted criterion used earlier. ${ }^{7}$ In contrast, the transition state of figure 5 shows no resemblance to any tautomer. Then, for this reaction, the Fukui function isosurface shape does not distinguish between Hammond and anti-Hammond types.

\section{Conclusions}

In general, DFT Kohn-Sham calculations provide good qualitative descriptions of intramolecular hydrogen shifts when large basis sets are used. Reaction and activation energies calculated with exchange and correlation hybrid functional B3LYP and triple- $\zeta$ basis sets are in very good agreement with $\operatorname{CCSD}(\mathrm{T})$ energies with the same basis sets. The Fukui function shows a small dependence on the basis set and the exchange and correlation functional. This analysis was made on the value of some integrals (moments) of the Fukui function and graphically, by comparing isosurfaces of the same property.

The evolution of the Fukui function describes the changes of the basic sites of the molecule along the reaction. These changes reflect the chemical nature of the involved species. A visual comparison of the transition state isosurfaces with those from the tautomers allowed us to make a Hammond-like identification in two of the three reactions.

\section{Acknowledgments}

Support from CONACYT (México) through a scholarship to NG-R and project funds is gratefully acknowledged. We also thank the Laboratorio de Supercomputo y Visualización en Paralelo (LSVP) at UAM-I for the access to its computer facilities.

\section{References}

1. March J 1992 Advanced organic chemistry: Reactions mechanisms and structure 4th edn (New York: Wiley)

2. Morrison R T and Boyd R N 1987 Organic chemistry 5th edn (Boston: Allyn and Bacon)
3. Cisneros G A, Liu H, Zhang Y and Yang W 2003 J. Am. Chem. Soc. 125498

4. Beak P 1977 Acc. Chem. Res. 10186

5. Rak J, Skurski, Simons J and Gutowski M $2001 \mathrm{~J}$. Am. Chem. Soc. 123 11695; Rodriquez C, Cunje A, Shoeib T, Chu I K, Hopkinson A C and Siu K W M 2000 J. Phys. Chem. A104 5023; Cardenas-Jirón G I and Toro-Labbe A 1997 J. Mol. Struct. (Theochem) 390 79; Cardenas-Jirón G I, Lahsen J and Toro-Labbe A 1995 J. Phys. Chem. 99 5325; Cioslowski J 1991 J. Am. Chem. Soc. 113 6756; Wong M W, Wiberg K B and Frisch M J 1992 J. Am. Chem. Soc. 114 1645; Tsuchiya Y, Tamura T, Fuji M and Ito M $1998 \mathrm{~J}$. Phys. Chem. 92 1760; Beak P, Covington J B, Smith S G, White J M and Zeigler J M $1980 \mathrm{~J}$. Org. Chem. 45 1354; Heinrich N, Koch W, Frenking G and Schwarz H 1986 J. Am. Chem. Soc. 108593

6. (a) Durant J L 1996 Chem. Phys. Lett. 256 595; (b) Torrent M, Duran M and Sola M 1996 J. Mol. Struct. (Theochem) 362 163; (c) Poater M, Sola M, Duran M and Robles J 2002 Phys. Chem. Chem. Phys. 4 722; (d) Baker M, Muir M and Andzelm J 1995 J. Chem. Phys. 1022063

7. Sola M and Toro-Labbe A 1999 J. Phys. Chem. A103 8847; Bulat F and Toro-Labbe A 2003 J. Chem. Phys. 1073987

8. Pérez P and Toro-Labbe A 2000 J. Phys. Chem. A104 1557

9. Parr R G and Yang W 1989 Density functional theory of atoms and molecules (New York: Oxford University Press)

10. Parr R G and Yang W 1984 J. Am. Chem. Soc. 106 4049

11. Bernholdt D E et al 1995 Int. J. Quantum Chem. Symp. 29475

12. Vosko S H, Wilk L and Nusair M 1980 Can. J. Phys. 581200

13. Becke A D 1988 Phys. Rev. A88 3098

14. Lee C, Yang W and Par R G 1988 Phys. Rev. B37 785

15. Becke A D 1993 J. Chem. Phys. 985648

16. Jalbout A F 2002 Mol. Phys. 243785

17. Cubbage J W and Jenks W S 2001 J. Phys. Chem. A105 10588

18. Alkorta I and Elguero J 2004 Tetrahedron Lett. 45 4127

19. Barone V and Adamo C 1996 J. Chem. Phys. 105 11007; Zhang Q, Bell R and Truong T N $1995 \mathrm{~J}$. Chem. Phys. 99 592; Jursic B S 1997 J. Mol. Struct. (Theochem) 417 89; Thummel H T and Bauschlicher C W 1997 J. Chem. Phys. 101 1188; Bach R D, Glukhovtsev M N and Gonzalez C 1998 J. Am. Chem. Soc. 120 9902; Rice B M, Pai S V and Chabalowski C F 1998 J. Phys. Chem. A102 6950; Tucker J M and Standard M 1998 J. Mol. Struct. (Theochem) 431 193; Jursic B S 1998 J. Mol. Struct. (Theochem) 430 17; Yoshizawa K, Shiota Y, Kang S and Yamabe T 1997 Organometallics 165058

20. Langenaeker W, De Proft F and Geerlings P $1996 J$. Mol. Struct. (Theochem) 362175 